\title{
The Normative Significance of Aristocratic Constitutions in Aristotle's Politics *
}

\author{
ELENA IRRERA \\ University of Bologna \\ elena.irrera2@unibo.it
}

\begin{abstract}
This paper contends that, despite evidences, Aristotle's view of aristocratic constitutions displays a heavily marked normative content. I argue that his understanding of aristocracy may be separated into four main strands: (i) an ideal type, based on the rotation of power of virtuous people over equally virtuous citizens (as evinced from a joint reading of Books III and IV); (ii) a type grounded on a fine blending of social classes, as emerging from a reading of Pol. IV, 7.1293b7-18 in the light of Politics IV,3.1290a24-29; (iii) a polity inclining toward oligarchy, which seems to lack any normative worth; (iv) an 'aristocratic polity', grounded on the political role of the middle class (Book IV.11). I shall propose that, in non-ideal conditions, type (iv) is the constitution which best accommodates (a) the need for stability and concord, (b) the search for an ideal of structural harmony and proportion among rulers and citizens.
\end{abstract}

Key Words

Aristotle, Aristocracy, Normative, Polity, Fine Blend

Recibido: 24/03/2015 - Aceptado: 11/12/2015

\section{Introduction}

Aristotle's treatment of aristocracy stands out in the taxonomy of constitutions outlined in the Politics as remarkably more elusive than his discussion of other forms of government. While in books III-VI the philosopher spends considerable time and effort in presenting a systematic account of different kinds of monarchy, oligarchy and democracy, he does not seem offer an equally wide-ranging picture of the rule by the excellent. 
Also, his references to aristocracy appear scattered throughout the text and do not seem to point to an exclusive qualifying criterion shared by any kind of aristocracy. For instance, he occasionally speaks of some forms of aristocracy whose core value is public concern for ethical excellence ${ }^{1}$, whereas, on other occasions, he mentions forms of government which, although generally labeled as "aristocratic", show a well-articulated plurality of values, including wealth, good birth $(\epsilon \dot{v} \gamma \epsilon \dot{\nu} \in \iota a)$, education $\left(\pi a \iota \delta \epsilon_{i} a\right)^{2}$ and sometimes even specific modalities of popular participation $^{3}$. Such constitutions will vary from each other depending on the chosen combination of eligibility criteria and on the priorities accorded to each. Within such forms of government, then, ethical excellence appears simply as one, and not as the only distinctive feature of aristocracy.

This paper contends that Aristotle's concern is addressed to the normative - rather than to the merely descriptive and taxonomic - aspect of the aristocratic form of government, and proposes that different levels of normativity are at work in Aristotle's treatment of aristocracy. I begin by examining Politics IV, 7, where three different kinds of constitutional forms are sketched out and presented as properly aristocratic: (i) a regime made up of those who are best simply on the basis of virtue (Pol. IV,

* I would like to address special thanks to Dr. Federico Zuolo for his useful and constructive comments on this paper.

1 See Pol. III, 7.1279a35-37; 13.1283b20-21; 15.1286b3-5; IV, 7.1293b1-5; 8. $1293 b 40$.

2 See Pol. III, 12.1283a9-22; IV, 3.1289b40-1290a2; 8. 1293b35-38; 8. 1294a19-25. See also IV, 4.1291b27-30, where Aristotle mentions the notables (oi $\gamma \nu \omega \dot{\rho} \iota \mu o \iota)$, who generally hold the highest offices in aristocracies, by pointing out that there are kinds distinguished by wealth, good birth, virtue, and education. On the plurality of requisites see WHIBLEY 1968, 111-112; cf. ARNHEIM 1977.

3 See for instance Aristotle's treatment of Sparta, Crete and Carthage in Book II of the Politics (sections 9-12). Cf. Pol. IV, 7.1293b7-18. 
7.1293b1-7); (ii) regimes differing from both oligarchy and polity, which Aristotle exemplifies by mentioning Sparta and Carthage (Pol. IV, 7. 1293b7-18), and (iii) those forms of so-called polity which incline more toward oligarchy (Pol. IV, 7.1293b18-21). I propose that only two among the three constitutional types outlined at Politics IV. 7 possess a normative side: the first one, which conveys the idea of a perfect virtue-based aristocracy, and the second one, where such an excellence coexists with and informs other criteria for political power.

In the second part of this paper I note that a crucial form of government of aristocratic flavour appears to be left out of the picture: a polity which does not incline either toward oligarchy or toward democracy, but is rather grounded in the presence and stabilizing role of the middle-class. This kind of polity, which Aristotle invites the reader to identify as a sort of aristocracy, is introduced at Politics IV.11 and presented as the best regime for most cities, championing a way of life that does not fall outside the intellectual and ethical range of most citizens and that, just for this reason, makes it possible for them to participate in the running of the polis. I argue that this is a fourth kind of aristocracy, which is not included in Politics IV.7 and discloses a normative factor different from those exhibited by the forms of aristocracy outlined in the above mentioned section. What approximates it to the level of a well-blended aristocracy is the degree of beauty employed in the blending of its political components.

I shall tease out the various normative aspects of aristocracy through two methodological patterns of political analysis that Aristotle himself makes available to the reader. The first paradigm, traceable at Politics IV.1, lays down the main tasks of political science and prescribes to study (i) the ideal constitution; (ii) which regime is fitting for which cities; (iii) the regime based on a presupposition; (iv) the regime which is most fitting for all cities. The second, which we find enucleated in a short passage of Politics IV.3 (1290a24-29), proposes a classification of constitutions based on the distinction between one or two regimes that are beautifully 
constituted and their deviations, which are described as "deviations from the well-blended harmony as well as from the best regime". I suggest that the "polity of aristocratic flavour" introduced at Politics IV. 11 can be better understood in its nature and goals in the light of the first pattern of analysis, whereas the aristocracies exemplified by Sparta and Carthage at Politics IV. 7 find conceptual support in the second paradigm.

\section{The First Kind of Aristocracy as the Best Constitution in Absolute}

In section 7 of Book IV of the Politics Aristotle lists three kinds and, on the whole, four different examples of aristocratic government. As for the first one, by referring to unspecified arguments which have already been laid out in the text, he speaks of a constitution made up by those who

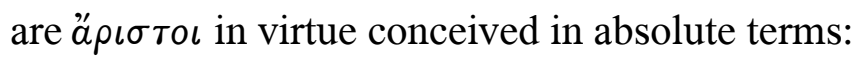

Now it is right to call aristocracy [the regime] we treated in our first discourses. Only the regime that is made up of those who are best in absolute ${ }^{4}$ on the basis of virtue, and not of men who are good in relation to some presupposition, is justly referred to as an aristocracy; for only here is it simply the case that the same person is a good man and a good citizen, while those who are good in others are so in relation to their regime (Pol. IV, 7.1293b1-7).

The above mentioned passage presents some interpretive problems. In the first place, although the qualifying trait of this first type of aristocracy is undoubtedly pure virtue, it is not entirely clear whether such a constitutional pattern is traceable in existing historical cities or it rather indicates the ideal constitution. Secondly, in case the aristocracy at issue

4 The English translation of the Politics I adopt in this paper is LORD 1984. Here, however, I have modified Lord's translation of the Greek $\dot{a} \pi \lambda \hat{\omega} s$ as "simply", given that in the following lines he opposes those who possess virtue $\dot{a} \pi \lambda \hat{\omega}$ s to those who possess it relatively to some presupposition. The adverb "simply" would rather emphasize the distinction between the first kind of aristocracy, which is the one grounded on pure virtue, and the remaining two kinds, which include other criteria of political power.

П Н Г Н / F O N S I (2016), 98-122 
were the ideal one, it might be wondered whether absolute excellence in such a regime is an exclusive prerogative of rulers.

Aristotle speaks of the first kind of aristocracy in very generic terms, which makes it hard to find an uncontroversial solution to the above mentioned interpretive issues. His appeal to what he calls "the first discourses" might represent the key to our understanding of this first kind of aristocracy. Some scholars maintain that, by invoking the "first discourses", Aristotle is referring the reader to Books VII-VIII, where he spends a great deal of effort to lay the grounds for the best possible constitution. Their view implies that the original position of these books in the text was antecedent to book $\mathrm{IV}^{5}$. An alternative possibility is stressed by Barker, who claims that the philosopher expressly addresses some remarks contained in Book III, particularly those concerning his wellknown distinction between the good man and the good citizen and the subsequent identification of the virtue of the good man as the one possessed by the good ruler in absolute ${ }^{6}$.

On my view, it is primarily to Book III that Aristotle is referring in his account of the best form of aristocracy outlined in Book IV. Remarkably enough, in the last section of Book III (Pol. III, 18.1288a37-39), he makes use of the same expression, i.e. "the first discourses", by pointing out not only that the main object of concern is the relationship between the virtue of the good man and that of the good citizen in the best city, but also and especially that the two virtues are one and the same, just as it is reported in Pol. IV, 7. 1293b3-5 with respect to the first kind of aristocracy. Nor is it a case that, in Book III, the picture of the ideal constitution makes a significant appearance as the framework of discussion

5 See for instance Newman 1887-1902; SUSEMIHL-HicKS 1894; WelLdON 1883. See also SIMPSON 1998, xvi-xvii. The same view is held by Lord, although his edition of the Politics retains the "traditional" order (see in particular 257, footnote 29).

6 See BARKER 1946, 186-187. For a better understanding of his stance see III, 4, particularly 1277a14-16 and 1277b25-30. 
chosen by Aristotle do set up the identity between the authentically virtuous man and the good ruler in absolute ${ }^{7}$. Assuming that it is primarily Book III that Aristotle has in mind while outlining the first kind of aristocracy in book IV, how can it help us to understand its nature and the implications of the identity between the good man and the good citizen established at VI.7? A plausible answer can be found in the emphasis accorded in Book III on the relationship between the distinctive virtue of the good citizen and that of the good ruler. The core of their distinction lies in the idea that, unlike the good citizen, whose distinctive virtue and political commitment simply presupposes an unquestioning abidance by the constitutional principles in force in his community, the good ruler is fully equipped with wisdom and a deliberative capacity informed by ethical excellence ${ }^{8}$. On the other hand, in the ideal city, which Aristotle selects as a suitable frame for his discussion ${ }^{9}$, the two virtues can be conceptually distinct without this preventing an individual from possessing both $^{10}$.

7 See Pol. III, 4. 1276b35-37: «By raising questions in a different manner, the same argument [i. e. the issue of the virtue of the good citizen and its relation to that of the good man] can be made concerning the best regime».

8 See Pol. III, 4. 1276b28-1277a20. Among those who emphasise a structural difference between the two virtues we find Develin (1973), who argues that the excellence of the ruler and the excellence of the ruled cannot coincide, not even within the framework of the ideal polis, whose well-being mainly depends on a well balanced diversification of functions. A similar view with regard to Book III is held by KRAUT 2002, 364-368), although he maintains that in Books VII-VIII the ideal city is described as one in which all citizens possess a correct understanding of well-being and have the equipment needed to live an ethically virtuous life (186, 359-360).

9 See footnote 7 above.

10 I refer the reader to IRRERA 2012, where the "coexistence thesis" is expounded, that is, the view that the virtue of the good citizen in the ideal city is perfectly compatible with a simultaneous possession of ethical and intellectual excellence. In other words, each and every citizen of the ideal city would be a potentially good ruler.

П Н Г Н / F O N S I (2016), 98-122 
As he stresses at Pol. III, 4.1277b11-13, learning how to become a good citizen is an indispensable step towards becoming a good ruler, just as it happens in the military sphere, where one learns to be a commander of cavalry by serving under other commanders ${ }^{11}$. Even more forcefully, at Pol. III, 13.1283b42-1284 a2 he claims that citizens should also be able to rule:

A citizen in the common sense is one who shares in ruling and being ruled; but he differs in accordance with each regime. In the case of the best regime, he is one who is capable of and intentionally chooses being ruled and ruling ${ }^{12}$ with a view to the life in accordance with virtue ${ }^{13}$.

Although no political community - not even the ideal one - can allow a simultaneous exercise of political power on its members' part, there seems to be a possible way of guaranteeing political participation to all: government in relays $\left(\mathcal{\epsilon}^{\prime} \nu \mu \epsilon^{\prime} \rho \epsilon \iota\right)$. As Aristotle makes it clear in the context of an investigation of the ideal constitution, such a political device is needed among persons who are free and equal in nature, for all cannot rule at the same time but each rules for a given period of time, so that, as a result, all have a share in ruling activity (Pol. II, 2. 1261a31-b9 $)^{14}$. In fact, such a method of allocation of political honours and duties is an appropriate normative response to the following principle: equal men

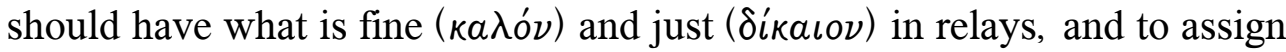
things unequal to similar individuals is contrary to nature, not to consider that nothing contrary to nature is fine (Pol. VII, 3. 1325b7-10).

«But there is also a sort of rule in accordance with which one rules those who are similar in stock and free. For this is what we speak of as political rule, and the ruler learns it by being ruled - just as the cavalry commander learns by being commanded, the general by being led, and [similarly in the case of] the leader of a regiment or a company». Cf. Plato, Laws I, 643e.

13 A similar position is held at Pol. III, 4.1277a25-27.

14

On the issue of government in relays see CAMBIANO 2000. Cf. IRRERA 2012, 145-146.

П Н Г Н / F O N S I (2016), 98-122 
The view that the good citizen of an ideal polis can also be a good ruler is theoretically sustained by the identity established by Aristotle between the virtue of the good citizen and that of the good man in the ideal community. Such a view, vaguely foreshadowed at Pol. III, $4^{15}$, finds its

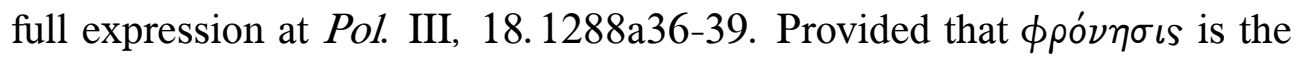
distinctive excellence of the good $\operatorname{man}^{16}$, the virtue of the good citizen, being the same as that of the good man, will not consist in mere conformity to the constitution in force, but will display itself in an exercise of autonomous deliberative excellence. It is just the latter excellence which entitles a good citizen to hold the highest political offices.

If equality is the underlying ratio of any form of government in relays, in the ideal constitution it will then take the form of equality based on virtue, provided that, in accordance with the leading principles of the best regime, each and every individual committed to ruling activity is expected

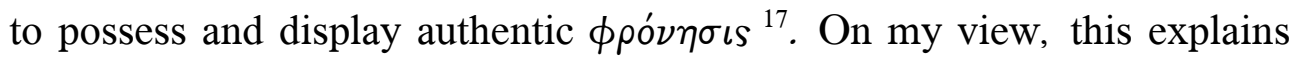
Aristotle's thought that, although the virtue of the good citizen is not the same as the virtue of the good ruler, the virtue of a citizen of reputation is held to be the capacity to rule and be ruled finely

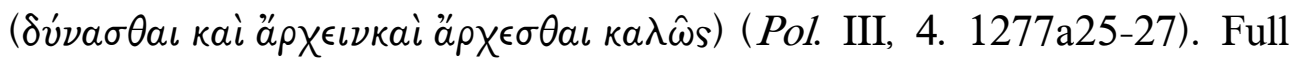
excellence and deliberative capacity will be required in the ideal community even of those who, at a given time, play the role of "simple" citizens $^{18}$; for there will come a time for them to have a share in the highest offices.

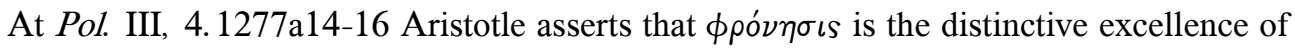
the good ruler, not of the good citizen. At Pol. III, 4.1277a20-21, however, he identifies the virtue of the good citizen with that of the good man by presenting it as a hypothesis. If we accept its validity, $\phi \rho o ́ \nu \eta \sigma \iota s$ will be possessed by the good citizen as well.

See Pol. III, 4. 1277a14-16, mentioned above.

See Pol. III, 4. 1277a14-16, 1277b25-26.

Cf. SIMPSON 1998, 191, 316.

П Н Г Н / F O N S I (2016), 98-122 
We might now wonder in what respects reference to the "first discourses" contributes to clarifying the nature of the "aristocracy of the best people". This kind of aristocracy, which he presents in terms of "the

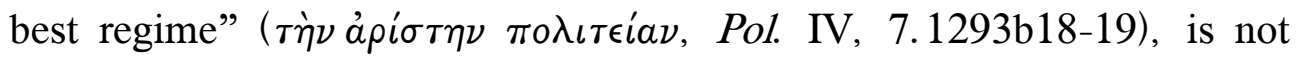
simply "the best aristocracy" among the three listed at Pol. IV, 7, but the best constitution in absolute. It is just this sort of constitution that acts as supreme regulative ideal for politicians and political scientists. In this respect, it seems to be endowed with a high normative worth, which explicates itself in the capacity to show what each and every virtuous citizen should be: a potentially good ruler. This suggests that aristocracy, being by definition government of the ä $\rho \iota \tau o \iota$ directed to the promotion of the common interest ${ }^{19}$, is not necessarily modeled on the pattern of an asymmetrical relation in terms of virtue between rulers and ruled, as it might otherwise happen in particular cases of historical constitutions ${ }^{20}$.

As Aristotle says at Pol. IV, 2.1289a31-32, to speak of the ideal polis is tantamount to speaking of aristocracy (plausibly the first aristocratic kind outlined in Pol. IV, 7). By relating the best constitution in absolute to a specific form of government, aristocracy, he gives a well-defined content to a purely abstract political category. What emerges from his reference to the "first speeches" in Pol. IV, 7 is not the willingness to detach the first aristocracy from the historically existing ones, but to specify and give substance to an abstract ideal, one which would otherwise risk to be the object of a sterile, utopian speculation.

\section{Aristocracy as a Well-tempered Constitution}

If reference to the "first discourses" made in Pol. IV, 7 has helped us to understand how the first aristocracy is to be conceived, it nevertheless does not explain the relationship subsisting between this first kind of

See Pol. III, 7. 1279a35-37.

On the Aristocracy based on the superiority of rulers see for instance Pol. III, 4 1288a915 and Pol. III, 18. 1288a32-39. 
aristocracy and the following two. Unlike the former, presented as a constitution based on possession and exercise of pure virtue, the latter kinds seem to involve a combination of qualities and selection criteria needed to perform a leading role in politics. We might wonder, then, whether such constitutions relate to the best one, and in what respects they depart from it. I propose that a suitable theoretical backup for the task is supplied by Aristotle in Pol. IV, 3. Here, by analysing some possible reasons for the existence of a plurality of constitutions, he explains that the constitution is an arrangement of offices ( $\dot{\eta} \tau \hat{\omega} \nu$ a $\rho \chi \hat{\omega} \nu \tau a \dot{\xi} \xi \varsigma)$ whose distribution takes place with respect to the political weight ( $\delta \dot{v} \nu a \mu \iota$ ) of those sharing in the constitution; constitutions are therefore as many as the ways of arranging magistracies in relation to the preeminence and the difference of the parts (Pol. IV, 3.1290a7-13). At any rate, as Aristotle is keen on emphasizing, it seems that the variety of constitutions can be reduced in the last analysis to two distinct kinds: democracy and oligarchy $^{21}$. By appealing to what seems to be a commonsensical view, aristocracy might be envisaged as a peculiar form of oligarchy, whereas the polity as a form of democracy. In the attempt to exemplify this concept by way of images understandable by anyone, he proposes not only the case of various winds that can be substantially reduced to two kinds, i.e. the northern and the southern, but also the case of different musical modes, which can be reciprocally combined in various ways. Emphasis on combination helps the readers' understanding of a different way of thinking of constitutions. In fact, Aristotle explains that, although his contemporaries are generally accustomed to conceive of constitutions in this way,

On the polarity between oligarchy and democracy in Aristotle's times see MULGAN 1991, particularly 311 .

П Н Г Н / F O N S I (2016), 98-122 
[...] it is truer ( $\dot{a} \lambda \eta \theta \dot{\epsilon} \sigma \tau \epsilon \rho o \nu)$ and better $\left(\beta \epsilon^{\prime} \lambda \tau \iota o \nu\right)$ to distinguish as we have, and say that one or two are finely constituted ( $\tau \hat{\eta} s \kappa a \lambda \hat{\omega} s \sigma v \nu \epsilon \sigma \tau \eta \kappa v i a s)$ and the others

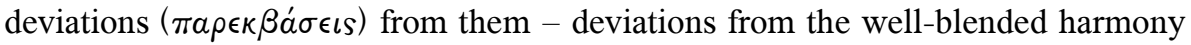

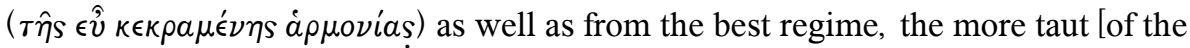
harmonies] being oligarchic and more like rule of a master, the relaxed and soft being popular (Pol. IV, 3. 1290a24-29).

His taxonomy is an alternative more theoretically sustainable and practically efficacious than the commonsensical paradigm. By initially exhibiting a substantial degree of uncertainty, Aristotle proposes "one or two" constitutions in the light of which the others seem to derive their nature as "deviations". The marking trait of the first two is a construction effected "in a beautiful way". In the case of the ideal constitution, the "good construction" stems from the adoption of virtue as the qualifying criterion for the exercise of political power alongside devices such as the already mentioned government in relays; as we have seen in the already mentioned Pol. VII, 3.1325b7-10, the latter is presented as "beautiful" and "consistent with nature".

Remarkably enough, however, Aristotle invites the reader to look at those constitutions which can be regarded as "beautifully structured" even when these are not grounded on the promotion of pure virtue. The beauty of the regime's inherent structure, in this second case, seems to come to the surface as the outcome and the visible manifestation of a good blending. This implies the existence of different qualifying criteria and social groups that do not necessarily share by their own nature a prominent concern for the valorization of virtue in political life; nevertheless, they result liable to be combined with the featuring qualities of different regimes thanks to the intervention of a wise lawgiver. In that case, the characteristic beauty of this second kind of constitution would not lie in any of its constitutive components, but rather in the blending itself. In the light of this taxonomic framework, oligarchies will no longer appear as suitable normative paradigms after which aristocracies are 
modeled. Vice versa, aristocratic forms of government and, in particular, the best one, are presented as a suitable cornerstone in the light of which oligarchies appear pure deviations. In a similar fashion, democracies are just deviations from the well-blended community, which at Pol. IV, 3. 1290a18 is named "polity" $\left.\left(\pi o \lambda_{\iota} \tau \in i a\right)\right)^{22}$.

As far as the polity is concerned, Aristotle has not yet provided a systematic treatment of such a constitutional form, nor has he mentioned the wide variety of forms this can take on. In the third book of the Politics, for instance, he simply includes it within the group of the right constitutions, that is, those regimes which aim at the common interest ${ }^{23}$, and confines himself to presenting it as the rule by a multitude $(\pi \lambda \hat{\eta} \theta o s)$ of people who do not possess virtue as a whole, but just some part of it, like the military class, whose distinctive virtue is simply of military kind ${ }^{24}$. Elsewhere, it is presented as a mixture of two constitutions, namely

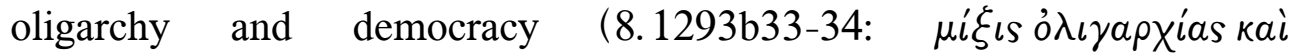
$\delta \eta \mu о к р а т і а)$ ) or, better said, a mixture of the well off and the poor ( $\mu i \xi \iota s$ $\tau \hat{\omega} \nu \in \dot{v} \pi o ́ \rho \omega \nu$ кai $\tau \hat{\omega} \nu$ ámó $\rho \omega \nu ; 9.1294 \mathrm{a} 16-17)^{25}$. The aspect of polity which strengthens the rationale of Aristotle's argument in Pol. IV, 3 (and makes it different from an unspecified "mixture" of various constitutions) is the presence of a "virtuous arrangement" of offices and groups. This is suggested by the idea that the blending is made "beautifully", that is, according to some kind of proportionality which ensures not only the inherent harmony of the polity, but also its stability. This, in turn,

On the identification of the well-blended constitution with a form of polity, see Simpson's comment on the passage. See Pol. III, 7.1279a37-1279b5.

On the involvement of the military class in the administration of the polity I refer the reader to IRRERA 2010, section $\mathrm{V}$.

Cf. Pol. IV, 8. 1294a23-24, where Aristotle draws a stark distinction between polity and aristocracy by specifying that only aristocracy mixes virtue to wealth and freedom, whereas polity is rooted exclusively on the mixture of the two latter properties. 
presupposes the presence of a wise project, that is, one which involves a "phronetic" attitude and possession of the typical deliberative capacity of wise lawgivers. What Aristotle mentions as a "polity", then, is a constitution approaching the nature of an aristocracy.

If the first kind of constitution enucleated in Pol. IV, 7 corresponds to the ideal constitution, the second one seems to incarnate just the kind of well-tempered constitution described in Pol. IV, 3. Let us then read the passage at Pol. IV, 7.1293b7-18:

Nevertheless, there are certain regimes which differ both from those that are oligarchically run and from so-called polity, and are called aristocracies. For wherever they elect to offices not only on the basis of wealth but also on the basis of desert, the regime itself is different from both of these and is called aristocratic. For indeed, in [cities] that do not make virtue a common concern there are still certain persons who are of good reputations and held to be respectable. Wherever, therefore, the regime looks both to wealth and to virtue as well as the people, as in Carthage, it is aristocratic; and so also those which, like the Lacedaemonian regime, look to two alone, virtue and the people and where there is a mixture of these two things, democracy and virtue.

It is worth noting that, in this second typology of constitution, virtue can be employed in the government of a city without being considered as the one and only requirement for accessing the highest offices; nor does virtue need to be publicly fostered among citizens as a value to cultivate and spread. A similar thought seems to reinforce the hypothesis that a polity can include respectable and virtuous people in ruling power, even though virtue is not regarded by lawgivers a "structural ingredient" of the mixture. The relevant examples put forward by Aristotle on this occasion are Sparta and Carthage. Within the present framework of discussion, he introduces them as cities which exhibit some concern for virtue in ruling power. Sparta, for instance, is described as a community whose constitutional nature involves a mixture of virtue and popular participation, whereas Carthage as one grounded on a mixture of the latter 
criteria to wealth. Such constitutions, being rooted on a multiplicity of presuppositions and qualifying criteria, cannot obviously be regarded as forms of a pure aristocracy; nor can they be identified as cases of oligarchy, for what oligarchic constitutions make open display of is exclusively wealth ${ }^{26}$, which is championed by those who abide by its principles both as a constituent of their personal view of happiness ${ }^{27}$ and as criterion for the selection of people to public offices. Within oligarchic forms of government, values like education, nobility of birth and deliberative virtue are not attached a prominent role, and they can emerge in and affect political life only in a contingent manner, that is, without enjoying public recognition. Sparta and Carthage seem rather closer to a blended constitution involving virtue. As far as Carthage is concerned, this seems to match the constitutional pattern of aristocracy outlined at Pol. IV, 8. 1294a23-25, that is, the one of a well-blended compound of wealth, popular participation and virtue. Wealth is instead omitted in the case of Sparta, which is described as rooted in a mixture of virtue and popular participation. Assuming the reliability of Aristotle's account of the Spartan constitution, such an omission might be explained by a supposed willingness of lawgivers to place higher emphasis on values which might prove factors of stability in a well-blended mixture. Desire for wealth, by contrast, might engender tendencies and attitudes opposed to virtuous practice, and it might also be a cause of internal conflict among the citizens.

In this respect, Sparta and Carthage can be identified as normative paradigms of a well-tempered constitution. Carthage, in particular, might be conceived of as a better aristocratic model than the one exemplified by

On the various kinds of oligarchy as regimes based on wealth see Pol. IV, 6.1293a1234. See WHIBLEY 1968.

27 See Book VII, 2.1324a8-10: «Those who ascribe living well to wealth in the case of a single person also call the city as a whole blessed if it is wealthy».

П Н Г Н / F O N S I (2016), 98-122 
Sparta, given that, on Aristotle's account, it adopts virtue as suitable criterion of selection not only of the highest offices, but also of lower ones, i.e. the which involve a widespread popular participation ${ }^{28}$. Also, by keeping the involvement of the many in political deliberations in high esteem, Carthage appears a solid, well organized constitution ( $\sigma \nu \nu \tau \epsilon \tau a \gamma \mu \epsilon \operatorname{c} \eta))$, where people acquiesce in the arrangement of its principles and no factional conflict arises between different social groups (Pol. II, 11. 1272b29-33).

In the light of the normative model proposed in Pol. IV, 7, the second kind of aristocracy, i.e. the one consisting in well-tempered models, is certainly less desirable than a perfect aristocracy purely founded on absolute virtue, but this is not a good reason to dismiss the second kind as a possible guiding pattern for less perfect constitutions, especially for those who are far away from the ideal regime. An example of the latter kind of constitution might be represented by the third kind of aristocracy mentioned in Pol. IV, 7: a polity inclined towards oligarchy (Pol. IV, 7.1293b18-21). It is not clear whether virtue is presupposed within the structure of the third aristocracy, as Aristotle rounds off the issue very quickly. Considering that in Pol. IV, 3 he has spoken of the generic tendency to mistake aristocracy for oligarchy, we might hypothesize that the latter kind of aristocracy be intended in the way in it is seen by common people ${ }^{29}$. In that case, it would not involve virtue and it might be regarded as diverging not only from the ideal aristocracy, but also and especially from the aristocracy based on a fine blend of qualities. Conceived as a deviation from the second kind of aristocracy outlined in Pol. IV , 7, oligarchy might be very close - or even identical with - a polity which resorts to expedients designed to reduce the multitude's political

See Pol. II, 11.1272b35-37.

See SimPSON 1998, 316-317. Cf. MulgAN 1977, 70. For a different view see Newman (1887-1902, 195-96), who conceives of this third kind of aristocracy as a true one for Aristotle. 
weight $^{30}$. Although this does not exclude the presence of virtuous people in the highest offices, considering that some respectable people descend by noble and rich families, virtue would not be publicly exhibited as a value of the constitution.

Notably enough, Aristotle does not offer here historical examples to elucidate the third kind of aristocracy. This might be due to the fact that he has no interest in presenting it as a model to follow. If such a kind of aristocracy is a real deviation, it cannot be taken on as a valid, inspirational model of aristocratic constitution. Still, the former kinds of aristocracy will offer it some clues on how to modify its underpinnings in the direction of a virtuous blend of factors.

\section{A Fourth Kind of Aristocracy}

Having established some possible theoretical connections between sections 3 and 7 of Pol. IV, it is now time to answer our original question: do the three kinds of aristocracy discussed so far exhaust the whole issue about aristocracy? I suggest that a plausible answer can be given after consideration of Book IV, 11. Here, as I believe, Aristotle offers an outline of a form of aristocracy which does not match any of the typologies of constitution outlined so far: one fully identifiable with a polity primarily grounded on the power of the middle class. Another question then arises: if the constitution at stake is a true form of aristocracy, why should Aristotle accord it a separate treatment with respect to the others?

In the first place, it should be noted that Aristotle's discussion of a polity based on the rule of the middle class is introduced by Aristotle within a search on the kinds of constitution that meet specific requirements, namely those of political science. We have already seen how perfect aristocracy turns out to coincide with the ideal constitution in

On the expedients worked out against popular participation in some polities see Pol. IV, 13. 1297a15-35.

П Н Г Н / F O N S I (2016), 98-122 
absolute. Among other things, this is precisely the first kind of constitution that a lawgiver endowed with political science should get to know, as we learn from Pol. IV, 1. As we have already seen, a lawgiver or politician endowed with political $\epsilon \pi \iota \sigma \tau \eta^{\prime} \mu \eta$ will also know what constitution fits different kinds of city, that is, what is the best one in given conditions, but also the best under a given presupposition. At this stage of our discussion, however, I shall put these three requisites aside and concentrate on the fourth and last one: knowledge of the constitution which fits most states in general (Pol. IV, 1.1288b33-35). This is an activity of a substantial practical import, for such a knowledge should be possessed by the virtuous lawgiver committed to an extremely difficult task: that of amending and ameliorating the constitution in which he finds himself operating. The wise lawgiver ought to introduce an arrangement of such a sort that the ruled could easily accept it (Pol. IV, 1.1289a1-3). The prescriptive aspect of such a research stands out forcefully in its prominence.

Only in the following section of the Politics we learn that the kind of constitution which Aristotle has in mind is one of aristocratic nature, that is, one in which the criterion of desirability is connected to the possibility of being applied to the majority of cities:

We must distinguish, first, the number of varieties of regimes, if indeed there are several kinds both of democracy and of oligarchy; next, which is the most attainable and which the most choiceworthy after the best regime, and if there is some other that is aristocratic ( $\epsilon \ddot{l} \tau \iota s \ddot{a} \lambda \lambda \eta \tau \epsilon \tau \dot{\chi} \chi \eta \kappa \epsilon \nu \dot{a} \rho \iota \sigma \tau о \kappa \rho а \tau \iota \kappa \grave{\eta})$ and finely constituted ( $\sigma v \nu \epsilon \sigma \tau \hat{\omega} \sigma \alpha \kappa a \lambda \hat{\omega} s)$ but fitting for most cities, which it is (Pol. IV, 1.1289b11-17).

The adjective $\sigma v \nu \epsilon \sigma \tau \hat{\omega} \sigma \alpha$ is generally applied to indicate poetical compositions made by parts $^{31}$; in association with the adverb $\kappa a \lambda \hat{\omega} s$, it indicates a fine arrangement of elements, and conveys the idea of a

See the verb sunistanai at Poetics, 17.1455a22, 8.1451a29. 
successful blending similar to the one emerging from the two patterns of well-temperate constitutions spelled out respectively in Pol. IV, 3 and 7.

When the blended constitution is a non-aristocratic polity, that is, one grounded in a simple balance between the rich and the poor, a way to attain its distinctive balance is to impart order in such a way that the part of the city that wants that constitution is superior to the part that refuses it (Pol. IV, 12.1296b15-16) or, even better, in such a way that each social class is inclined to endorse the preservation of the constitution. A similar case occurs when one thinks that the constitution champions the same values by which one abides, i.e. those he identifies happiness with. In a well-organized polity each member believes to be well-represented, without seriously considering the possibility that people belonging to different social classes might fully accept the same constitution and perceive an equal sense of satisfaction ${ }^{32}$.

Such a balance, though, proves extremely fragile and precarious, and just a few imperceptible moves would be sufficient to allow one part to acquire a position of political prominence. Not only in ill-balanced polities, but even in aristocratic constitutions do we find that revolutions do burst out because just a few people take part in political honours. As Aristotle explains, the starting point of a polity's decline is the lack of a fine blending between democracy and oligarchy, whereas that of an aristocracy's change for the worse is the lack of an appropriate mixture between the two above-mentioned elements and virtue ( Pol. V, 7.1307a511). Historically relevant examples of cases like this are Thurii and Locris, in which rebellions were undertaken by the $\delta \hat{\eta} \mu o s$, as political offices and wealth were in the hands of just a few notables. Such things,

32 A clear example of a well-tempered constitution accepted by anyone is the one in which the polity which results from the mixture can be spoken of as either a democracy or an oligarchy (Pol. IV, 9.1294b14-17). Cf. IRRERA 2010, section III; WHIBLEY, 1968, 16 17.

П Н Г Н / F O N S I (2016), 98-122 
as Aristotle points out, would never have happened in a democracy and

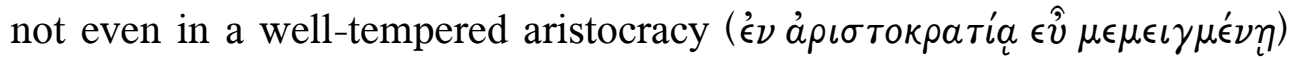
(Pol. V, 7.1307a27-40).

What is then the connective element between rich and poor that has the power to guarantee a stable, and not simply temporary, fine blending? Aristotle proposes that it is the political role of the middle class. Such a constitution is the best not in absolute terms, but only in relation to a way of life which is possible for most to participate in. It is also meaningful that, in such a context of discussion, Aristotle introduces aristocracy as a benchmark for the understanding of the constitutional form under examination. Here, we read that there are various kinds of aristocracy, some of which fall outside the range of most cities, whereas others approach that form of government named "polity" (Pol. IV, 11.1295a3133). What is most relevant for our purposes is the remark at Pol. IV, 11. 1295a33-34: "hence we may speak of both as one". Although far from the perfect city, there is still a sense in which the polity Aristotle is going to introduce can approximate the level of an imperfect aristocracy.

In the impossibility to promote a form of government which endorses possession and exercise of perfect virtue for each and every citizen, it is still legitimate to maximize what constitutes the general character of ethical virtue, that is, its being an intermediacy between excess and deficiency. Such an intermediacy is not a political solution externally imposed to the city by lawgivers, namely the one consisting in the attempt to lead opposed classes to a mediation point, but it is one which must be interiorized by individuals, at least by those entrusted with political offices of high responsibility. A similar constitution is highly unlikely to be entirely formed by moderate citizens, even more so because, as Aristotle himself explains, there are three different classes of citizens: the extremely rich, the extremely poor and those who stand in-between them (Pol. IV, 11.1295b1-3). The well-off and the poor will develop habits far from a healthy intermediacy just respectively in virtue of their excessive possess 
or lack of material resources. As Aristotle however explains, since what is moderate is by general agreement the best, it is evident that even in the case of the goods of fortune a moderate possession will be the best, given that what is moderate is more well-inclined to obey reason, while for one who is exceedingly handsome, strong, well born or wealthy, or the reverse of these things, it is difficult to abide by the prescriptions issued by reason (Pol. IV, 11.1295b3-9). Despite its contingent character, an excessive or defective possession of goods, then, either material like wealth or immaterial like beauty, strength and nobility, exerts a profound and decisive influence on the shaping and the reinforcement of nonvirtuous ethical inclinations. More specifically, those in possession of an exceeding quantity of goods not only are not well-inclined to be subjected to the ruled, but are themselves unable to exert ruling power in the appropriate way. Those who live in conditions of extreme poverty, on the other hand, need the resources, strength and self-confidence required to engage in political deliberative process, which is why they appear more well-inclined to be ruled rather than to rule. Unlike the extremely rich and the extremely poor, whoever possesses a moderate quantity of resources is highly likely to obey and to exert reason more easily and appropriately (Pol. IV, 11.1295b9-1296a18).

It is reasonable to suppose that, rather than presenting the picture of a state entirely constituted of citizens belonging to the middle-class, Aristotle is staging a normative model which makes use of the middleclass as its pivotal underpinning. The political role of the middle class turns out to constitute a balancing power between opposite forces ${ }^{33}$, that

As the pivotal underpinning of a well-conducted political community, the middle class cannot emerge from a simple combination of the rich and the poor. See for instance FRANK 2005, 5, who explains that it rather emerges «when, on the basis of their selfinterests, the few and the many cooperate to their mutual advantage to produce a common good that is something more than a aggregation of their discrete self-interests».

П Н Г Н / F O N S I (2016), 98-122 
is, as the ideal center of a symmetry which, without its presence, would degenerate and slide into political disorder and injustice. As Aristotle concludes,

It is clear, therefore, that the political partnership that depends on the middling sort is best as well, and that those cities are capable of being well governed in which the middling element is numerous - most particularly if it is superior to both [of the other] parts, but if not, superior to either of them; for when added to one it will tip the scale and prevent the opposing excesses from arising (Pol. IV, 11. 1295b34-39).

As a consequence, it is a truly good fortune for those who are engaged in politics to own a middling property, because where some possess too many things and others nothing, either an extreme democracy or an unmixed oligarchy are doomed to come into being. In the light of such possible outcomes, the middling sort of constitution will certainly appear the best, because it alone is without factional conflict. In fact, where the middling element is numerous, factional conflicts are less likely to occur (Pol. IV, 11.125b34-1296a2).

A second aspect which positively affects the outcomes of political activity bears on the education endured by wise lawgivers. For it is generally to the middle class that belong lawgivers like Solon and Licurgus (Pol. IV, 11.1296a18-21). The lawgiver coming from the middle class must be aware of the stabilizing power of the intermediacy paradigmatically exemplified by his original social class, and must convert intermediacy itself into a source of virtuous political activity. This is why, as Aristotle points out at Pol. IV, 12. 1296b34-38,

The legislator should always add those of the middling sort [to the dominant class] in the regime. If he enacts oligarchic laws, he ought to aim at the middling sort; if democratic ones, he ought to attach these to them.

Cf. 163-178, where she contends that a middle class can emerge on through an already existing friendship within the polity. 


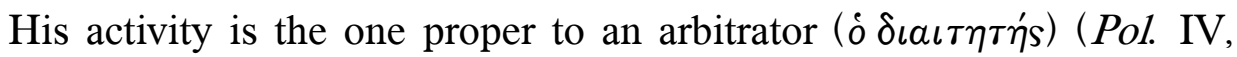
$11.1297 \mathrm{a} 5)$, that is, as the author of the fine blending which shapes such a constitution. His wise intervention, being firmly grounded in moderate attitudes, proves that the fine mixture is not a purely apparent harmony, but a stable, structural property of well governed cities, capable of sorting out beneficial effects both on political life itself an on the members of the community. The better the mixture in the polity, Aristotle says, the more lasting it will be. It is also indicative that

Many of those who want to set up aristocratic regimes as well [as polities] thoroughly err not only by the fact that they distribute more to the well off, but also by deceiving the people. For in time from things falsely good there must result a true evil, and the aggrandizements of the wealthy are more ruinous to the polity than those of the people ( Pol. IV, 13.1297a7-13).

A good blending relying on the middle class might certainly be effected by some members of the middle class, but a simple good propensity to moderation is not sufficient. For, as Aristotle has already stressed in Book

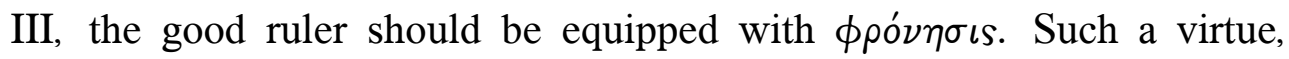
being accompanied by the rest of ethical virtues ${ }^{34}$, will secure the right step in deliberative processes at the political level. It is just this virtue,

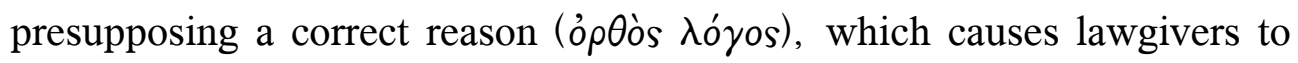
think of the middle class as a potential counterbalancing power in the polity. Placing moderate individuals in strategic political offices will prove a successful strategy for both a good blending and its stability ${ }^{35}$.

On the connection between $\phi \rho o ́ v \eta \sigma \iota s$ and the rest of ethical excellences see $N E \mathrm{VI}$, 13. 1145a6-7.

35 As Aristotle explains at Pol. V, 1.1302a13-15: «Moreover, the regime made up of the middling elements is closer to the [rule of] the people than to [rule of] the few, and this is the most stable of regimes of this sort».

П Н Г Н / F O N S I (2016), 98-122 
Besides stressing an expediential aspect of the search for a good order and stability in the city, Aristotle's argument on the well-ordered city invites us to believe that there is also an "aesthetical" reason in support of a fine blending of political components. As we have seen with respect to Pol. IV, 3, the mixture of parts in a well-tempered constitution is realized "in a beautiful way" ( $\kappa a \lambda \hat{\omega} s)$, and so is a polity so well-organised that it can be called both a democracy and an oligarchy (Pol. IV, 9.1294b1317). This may allow us to view a hypothetically perfect polity, that is, one that can be regarded as a kind of aristocracy, in terms of a regulative ideal $^{36}$ capable of inspiring virtuous lawgivers and politicians committed to political activity in deviant constitutions, especially when the wellarticulated blend on which it is based involves a substantial participation of people belonging to the middle class.

This is why a polity which manages to satisfy both the need of beauty and that of stability can be identified as an aristocracy proper ${ }^{37}$. We can therefore speak of a fourth kind of aristocracy, that is, one which Aristotle is keen on keeping separate from the others in virtue of its peculiarly paradigmatic nature. As a constitution approachable by most communities, such a kind of aristocracy possesses a higher practical relevance than the ideal constitution itself, representing a pattern to be emulated by wise lawgivers.

This point is well emphasised by RowE 2000, 367-368. With reference to Pol. IV, 1 Rowe explains that Aristotle himself clearly says that «writing about the 'best absolutely' and saying what is 'of practical use' are not only compatible, but are actually both to be properly regarded as parts of the business of political philosophy'» (367).

On the proximity of the polity to aristocracy see ROWE 2000, 380, 384. Cf. BLUHM 1962. However, as Bluhm points out at 749, though the life of the polity is similar to that of the ideal state, Aristotle says that the polity falls short of the ideal (Pol. IV, 11.1295a25-40). There are in fact some inequalities which are absent in the ideal state, such as the existence of wealthy and impoverished minorities. On this point see also JOHNSON 1988, 191. 


\section{Bibliography}

ArnHeIM, M.T.W. (1977), Aristocracy in Greek Society, London, Thames\&Hudson Ltd.

BARKer, E. (1946), The Politics of Aristotle, Oxford, Oxford University Press.

BluHM, W.T. (1962), "The Place of the "Polity" in Aristotle's Theory of the Ideal State", «The Journal of Politics» 24, 743-753.

CAmbiano, G. (2000), “Aristotele e La Rotazione del Potere”, in: M. MigLiORI (ed.), Il Dibattito Etico e Politico in Grecia tra il v e il iv Secolo, Napoli, La Città del Sole, 529-544.

Develin, R. (1973), "The Good Man and the Good Citizen in Aristotle's Politics", «Phronesis» 18, 71-79.

Frank, J. (2005), A Democracy of Distinction. Aristotle and the Work of Politics, Chicago, University of Chicago Press.

IrRERA, E. (2012), “Can a Good Citizen be a Good Ruler? An Answer from Aristotle's Politics", «Acta Philosophica» 21, 127-148.

IRRERA, E. (2010), "Being a Good Ruler in a Deviant Community. Aristotle's Theory of the Polity", «Polis» 27, 58-79.

JoHnson, C. N. (1988), “Aristotle's Polity: Middle or Mixed Constitution?”, «History of Political Thought» 9, 189-204.

Kraut, R. (2002), Aristotle, Oxford, Oxford University Press.

LORD, C. (1984), Aristotle. The Politics. Translated with an Introduction, Notes and Glossary, Chicago, University of Chicago Press.

Mulgan, R. (1977), Aristotle's Political Theory, Oxford, Oxford University Press.

MulgAN, R. (1991), "Aristotle's Analysis of Oligarchy and Democracy", in D. KEYT, F. D. Jr. Miller (eds.), A Companion to Aristotle's "Politics", Oxford, Blackwell, 307-322.

NeWman, W.L. (1887-1902), The Politics of Aristotle, I-IV, Oxford, Clarendon Press.

Rowe, C.J. (2000), “Aristotelian Constitutions", in: C. J. RowE, M. SCHOFIELD (eds. ), The Cambridge History of Greek and Roman Political Thought, Cambridge, Cambridge University Press, 366-89.

Simpson, P.L.P. (1998), A Philosophical Commentary on the Politics of Aristotle, Chapell Hill-London, The University of North Carolina Press.

SUSEMIHL F. -HICKS, R. D. (1894), The Politics of Aristotle, London, Macmillan.

П Н Г Н / F O N S I (2016), 98-122 
The Normative Significance of Aristocratic Constitutions in Aristotle's Politics

WeLLDON, J.E. C. (1883), The Politics of Aristotle, London, Macmillan.

WhiBley, L. (1968), Greek Oligarchies. Their Character and Organization, Roma, Edizione Anastatica. 